\title{
Innovation Ecosystem with Chinese Characteristics: Experiences and Lessons from Small and Medium-sized Manufacturing Enterprises
}

\author{
Yu WANG
}

\begin{abstract}
After four decades of reform and opening up, the market economy cannot only develop healthily under the socialist system, but also it is more active in capitalist society. This paper compares the development of Chinese enterprises' innovation ability with neighboring countries, selects small and medium-sized manufacturing enterprises as a research sample of market economy, and summarizes the ecological road of enterprise innovation between China and neighboring countries, from imitation to innovation. Nowadays, many Chinese products have already competed in the global market in terms of cost, quality, and innovation. China's product innovation performance has been recognized worldwide. The purpose of this paper is to study the unique step of China's innovation, based on China's national conditions, and adhere to the socialist market economy with Chinese characteristics. Some industrial parks have even surpassed Japan and South Korea. This paper collects field survey data from small and medium-sized manufacturing enterprises (SMMEs) in Suzhou, China. The study shows that the innovation ecosystem with Chinese characteristics can be roughly divided into three steps, which are slightly different from Japan and South Korea. How to improve the skills and competitiveness of China's SMMEs in three unique steps will help the improvement of the SMMES innovative ecosystem and enhance the competitiveness of enterprises.
\end{abstract}

Keywords: Chinese characteristics; innovative ecosystem; market economy; reform and opening up; small and medium-sized manufacturing enterprises

\section{INTRODUCTION}

In order to achieve rapid economic development, China has greatly improved its innovation capability by imitating the development model of independent innovation through decades of learning and cooperation with foreign companies. However, "Made in China" is labelled as cheap and inferior products in international trade. Most small and medium-sized export companies have low-end products, only low-cost labor at the bottom, and low benefit. SMMEs have long consumed human resources, by the main low-cost product route (Freel, 2000) [10]. China's innovation achievements are not widely recognized. In order to change the impression that many countries regard China as a "repetitive imitation" or even an "infringement" country, the initiative has transformed itself from "Made in China" to "Designed in China, Created in China". In recent years, China has proposed to get rid of excessive dependence on foreign technology through independent innovation. In the step of independent innovation, the most important thing is how Chinese companies can develop an innovation ecosystem with Chinese characteristics that suit them, and provide theoretical guidance for the coordinated development of innovative elements by better facing international market competition.

At present, small and medium-sized manufacturing enterprises have become the main force in China's economic development, providing a huge innovation driving force in the development of China's market economy and manufacturing ecosystem, and contributing an important force to economic construction. In terms of the number of companies, SMMEs in developed countries such as the USA, Japan, and Europe have accounted for more than $98 \%$ of the number of companies. Siu et al. [11] pointed out that China's SMMEs in socialist countries with Chinese characteristics were not recognized by the society in the past, which is also a factor hindering the development of China's SMMEs. In addition, innovation is oriented to the symbiotic evolution of the innovation subject and the external environment (Mei Liang et al.,
2014) [1]. Poor technical capabilities also inhibit the development of new products by China's SMMEs. Tang Jianrong et al. [2] started from the interaction between industry and ecosystem and characterized the innovation ecosystem as a pressure subsystem, a state subsystem, and a response subsystem. Li Qiwei et al. [3] took 18 industries and 278 institutions in Tianfu New District, Sichuan as empirical objects. Therefore, SMMEs are more likely to rely on cooperation among enterprises, than horizontal cooperation with governments, research institutes, and universities. China's SMMEs can respond to market trends, SMMEs can carry out new product innovation research and development more effectively than large companies can, and differentiate their brands.

At present, most of the existing investigations have summarized the innovative development step of China's SMMEs. Recent studies have equated the development step of Chinese product innovation with imitative innovation or the early development step of Japan and South Korea. Therefore, how to improve the efficiency of product innovation in today's fierce market competition is very important for China's SMMEs. This article first analyzes the status quo of China's SMMEs, and then introduces the use of samples and research methods, and proposes enlightenment for research and practice. Finally, through a summary of this article, it points out the shortcomings encountered in the development of SMMEs and their limitations, which briefly outlines the direction of future research.

\section{INNOVATION ECOSYSTEM}

The innovation ecosystem is the process of assimilation, then of adjusting technology, and finally of doing the innovation and optimization. The imitation helps the company's product development, and imitation can enhance the company's competitiveness (Cheung, 2011) [7]. In the actual process, most companies gradually build innovative capabilities by imitating competitors' technologies. Many researchers have shown that Japanese and South Korean manufacturing can promote the growth 
of corporate profits. Will China's SMMEs in the country follow the successful innovation ecosystem?

\subsection{Japanese Innovation Ecosystem}

The development of learning in Japan has written records that the process of Japanese corporate ecological innovation can be divided into three steps, namely "obedience- decomposition- separation" (see Fig. 1). Until now, this innovative ecosystem concept still affects the Japanese nation. In the initial step, the corresponding laws were observed and copied until the skills could be mastered. The second step is to gradually get rid of the "old" practice. Finally, students will deviate from traditional methods and establish their own values to achieve transcendence. After World War II, in order to line with the development speed of developed countries, Japan actively learned new skilled theories and practices, and the rise of its manufacturing industry was incredible. SMMEs have obtained many foreign license technologies, advanced manufacturing equipment, and capital.

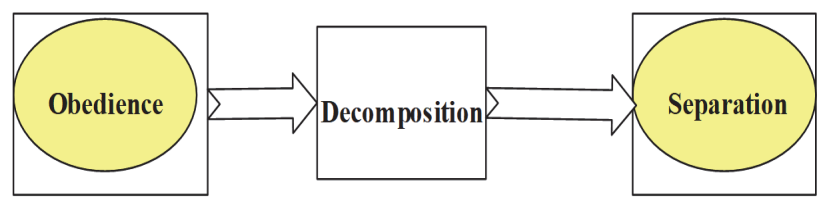

Figure 1 Japan's innovation ecosystem

Quality control and innovation management methods are applied to the traditional Japanese learning process. Japan imitates competitors' products decomposing and learns from them to enhance their competitiveness. However, Japanese companies will decompose existing skills, master new technologies and quickly localize them and transform them into new products. SMMEs separate their own unique skills while accepting new knowledge, in order to achieve a higher level of innovation.

\subsection{Korea Innovation Ecosystem}

The achievements of South Korea's modernization are largely influenced by the positive guidance of government policies. SMMEs promote the development of innovation capabilities through preferential policies such as local loans and foreign exchange. In the early step of industrialization, companies such as Samsung, Hyundai and LG sent technicians to foreign companies or joint ventures to learn in order to achieve proficiency in new technologies and to innovate on this basis. In the context of South Korea's knowledge transition, the rapidly changing business competition requires companies to continuously improve or create new technologies. In addition, the Korean manufacturing innovation ecosystem has gone through three steps, which are repetitive imitation, created imitation, and breakthrough innovation (see Fig. 2).

South Korean SMMEs play a decisive role in the repetitive imitation step, that is, Korean companies adopt employee incentive mechanisms. In the transfer and the dissemination of foreign new technologies in enterprises, the Korean government establishes technology incentive mechanisms. Korean companies strive to obtain advanced technologies. In the created imitation step, Korean companies increase the value of their products at a higher level.

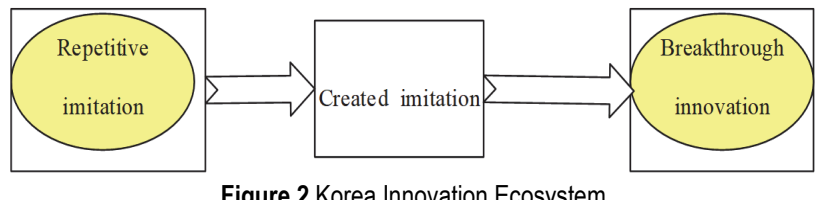

Figure 2 Korea Innovation Ecosystem

\subsection{Innovation Ecosystem with Chinese Characteristics}

Chinese companies are catching up, the different steps of product innovation development are obvious, which have gradually achieved industrialization. In 2016, the "1 $1{ }^{\text {th }}$ Five-Year Plan" proposed by the Chinese government puts innovation as the core of the national strategy. As the country's economy develops, mass entrepreneurship and innovation have become important engines for economic transformation and growth. The state strives to promote the transformation of scientific and technological achievements, encourage scientific research personnel to innovate and start businesses, promote the reform of the commercial system, and create a market environment conducive to innovation and entrepreneurship. Chinese companies in the context of the rapid development of Internet technology and other logistics technologies can obtain the latest science and technology. Chinese companies can gain sufficient knowledge to support the development of new products. The "imitation" step of Chinese companies is not only simple "copy and imitation" or "obedience", but has also a greater goal of imitation strategy, which is to reduce the risk of product innovation failure.

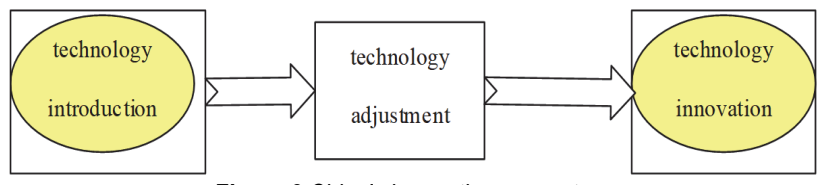

Figure 3 China's innovation ecosystem

Therefore, the innovation ecosystem with Chinese characteristics: technology introduction-technology adjustment-technology innovation can be seen in Fig. 3 . The initial step of SMMEs product innovation can be named "technology introduction". The word "technology introduction" in Chinese has the ability to introduce and adopt the knowledge or experience of others to achieve better results. Similarly, the next step of product innovation and development needs to adjust and improve existing products, which can be described by another Chinese word "technology innovation". Most Chinese companies see this step as a transitional step between "technology imitation" and "technology innovation". Therefore, Chinese companies in the "technology adjustment" step are closer to innovative products than the "imitative innovation" and "technology subdivision" steps of South Korea and Japan. In the innovation step, it is taken from the Chinese character "technology innovation", which means changing the original design and creating new products to obtain more profits. However, due to resource constraints and other obstacles, China's SMMEs can develop new products. 


\section{ANALYSIS OF CHINA'S INNOVATION ECOSYSTEM 3.1 Construction of Innovation Ecosystem}

Based on the above ecological perspective, the innovation ecosystem has constructed an innovation ecosystem for regional SMMEs (Fig. 4). In the innovation environment with Chinese characteristics, the innovation platforms of SMMEs bring together enterprises, governments, colleges and universities, and social service organizations to form an innovation ecosystem, which is interconnected under the influence of various factors. The role of government departments is to provide mutual guidance and supervision among the government and universities, which provides a platform for the transformation of scientific and technological achievements. Service agencies coordinate common interests, realize intellectual property protection, maintain and regulate the innovation ecosystem, realize the healthy development of the system, and realize cooperative innovation and mutual benefit among member companies. At the same time, the input of the innovation ecosystem comes from user needs and innovation resources, which are incubated by scientific research institutes of universities, such as university science parks. In the end, the output of SMMEs is innovation results, which are improved according to customer feedback, and the next input feedback is realized through the innovation platform.

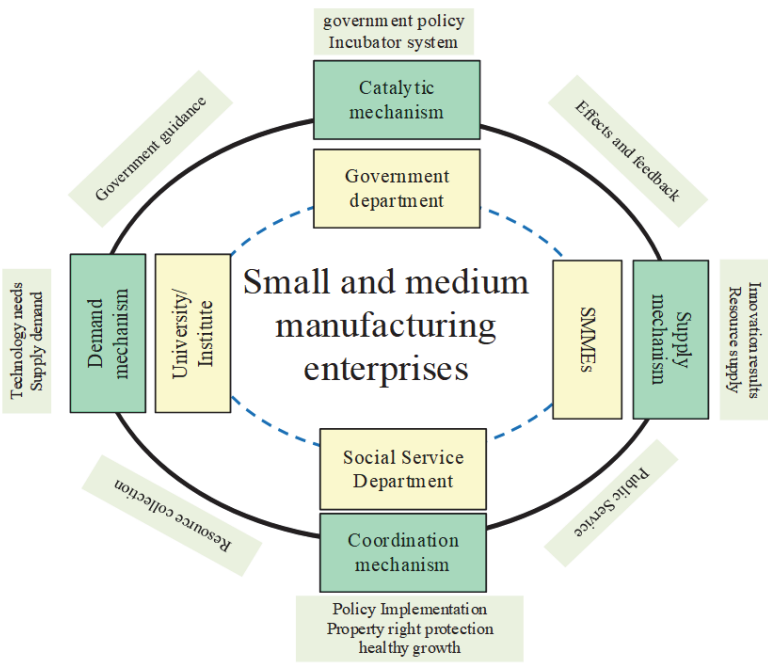

Figure 4 The relationship between the elements of the SMMES innovation ecosystem

This paper builds an innovation platform for SMMEs with Chinese characteristics (Fig. 5). Innovation platforms should actively improve service performance, integrate various technological innovation elements and resources in the innovation ecosystem, and provide effective solutions one by one according to the different characteristics and requirements of enterprise users.

First, this paper establishes a SMMEs innovation alliance centered on university scientific research institutes, financial institutions and relevant government departments and regional universities as the centre, and establishes a communication platform. They cooperate to innovate resource demand and supply, and provide supporting training services. Second, the SMMES collaborative innovation platform will use the innovation service platform as a bridge, guided by government support policies, and will use the realization of information technology to shorten the process of financial institutions providing financial support for SMMEs. In the innovation process, the SMMES Alliance Service should effectively supervise the platform-based innovation and cooperation process through a control mechanism to ensure the smooth progress of cooperation and innovation.

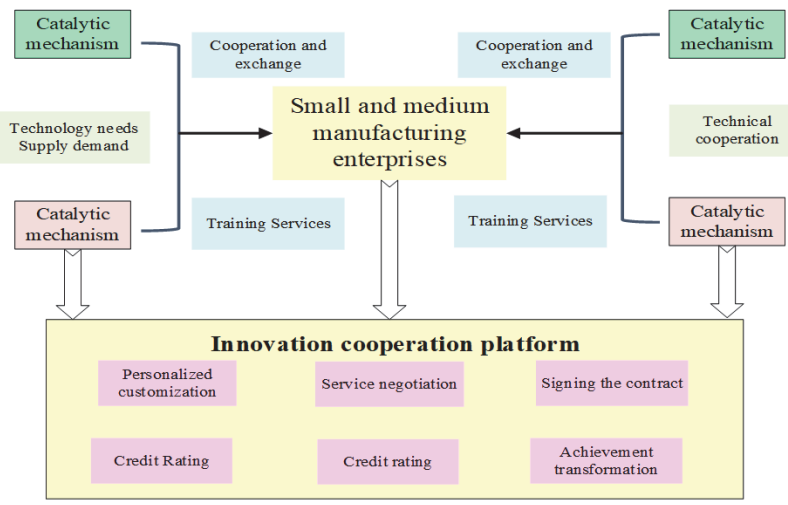

Figure 5 Process analysis of SMMEs innovation ecosystem

\subsection{Data Collection}

Through the research on the innovation ecosystems of Japan, South Korea, and China, this paper has analyzed and compared the three development steps of each country. This paper can further analyze the experience and lessons of China's innovation based on a series of field visits and questionnaires. Tab. 1 is a relevant economic data comparison of SMMEs in some countries.

Table 1 Economic data Comparison of SMMEs in some countries

\begin{tabular}{|l|c|c|c|}
\hline & USA & Japan & China \\
\hline $\begin{array}{l}\text { Accounted for the total number of enterprises } \\
/ \%\end{array}$ & 99 & 99.8 & 99.7 \\
\hline Contribution rate to economic growth / \% & 52 & 47.6 & 55 \\
\hline Proportion in employment / \% & 68 & 67 & 76 \\
\hline
\end{tabular}

Tab. 1 clearly shows that for countries SMMEs are an indispensable part of economic construction. Affected by the increasingly complex domestic and international economic operating environment, the development of the country's SMMEs is currently facing severe challenges.

$70 \%$ to $80 \%$ of SMMEs are still exporting labor, lacking core competitiveness, and even facing survival difficulties. According to data from the National Bureau of Statistics of 2019, there were 384000 SMMEs across the country, the growth of 4000 enterprises from the end of 2017. Among them, there are 53000 medium-sized enterprises, $14.3 \%$ of the number of SMMEs; 361000 small enterprises account for $85.7 \%$ of the number of SMMEs.

\begin{tabular}{|c|c|c|c|c|}
\hline \multirow{2}{*}{ Quantity / sum } & \multicolumn{3}{|c|}{ SMMEs (Ten thousand) } & $\begin{array}{l}\text { Increments } \\
\text { (Ten thousand) }\end{array}$ \\
\hline & \multicolumn{3}{|c|}{38.4} & 0.4 \\
\hline Location & East & Central & West & \\
\hline Quantity & 21.2 & 12 & 5.2 & \\
\hline Proportion / \% & 57.8 & 28.1 & 14.1 & \\
\hline
\end{tabular}

The number of SMMEs in the eastern, central, western, and northeastern regions was 212000, 92000, 52000, and 28000 , respectively, representing an increase of $0.8 \%$, 
$6.2 \%, 5.6 \%$, and $1.0 \%$ year-on-year, which is accounting for $57.8 \%, 23.9 \%, 14.1 \%$, and $5.2 \%$ of the number of SMMEs respectively. In terms of provinces and cities, provinces and cities with more than $5 \%$ of SMMES households are mainly located in the eastern and central regions, including 8 provinces including Jiangsu,
Guangdong, Hubei, Shandong, Zhejiang, Henan, Fujian and Anhui. 267000 enterprises Households account for $56.1 \%$ of the number of SMMEs. Among them, 350000 SMMEs in the manufacturing industry, the synchronous growth is $1.3 \%$, which is accounting for $94.6 \%$ of the number of SMMEs.

\begin{tabular}{|c|c|c|c|c|}
\hline & East & Central & West & Northeast \\
\hline Operating income & 42.6 Trillion & 20.8 Trillion & 11.7 Trillion & 3.2 Trillion \\
\hline The total profit & 2.3 Trillion & 1.9 Trillion & 0.6 Trillion & 0.18 Trillion \\
\hline Loss / \% & 11.8 & 7.6 & 16.7 & 18.4 \\
\hline R\&D staff & 62 & 25 & 11 & 7 \\
\hline Number of patent applications / \% & 24.3 & 19.2 & 13.8 & 8.6 \\
\hline Proportion of research funding investment / \% & 3 & 1.2 & 0.4 & 0.2 \\
\hline
\end{tabular}

In 2018, the operating income of the eastern, central, western, and north-eastern regions of the country exceeded the trillion mark, but the gap is obvious. The eastern region as a whole is much better than the rest of the country, with operating income of 42.6 trillion ranking first, and the total profit is 2.3 Trillions. Relatively speaking, the central region has the highest profit margin, accounting for about $9 \%$. In addition, in the eastern and central regions, the proportion of R\&D 10000 people in scientific research investment is relatively high, $24.3 \%$ and $19.2 \%$ respectively.

\subsection{Data Analysis}

In the practical phase, we conducted case studies on China's SMMEs across the country. First, SMMEs are keen on new product development and are willing to share their experience. Secondly, these companies have been engaged in product innovation and understand the new technologies of current products. In the system data analysis step, the data is classified according to the "technology introduction- technology adjustment-technology creation" relationship, and then the different situations of similar events are compared for induction verification.

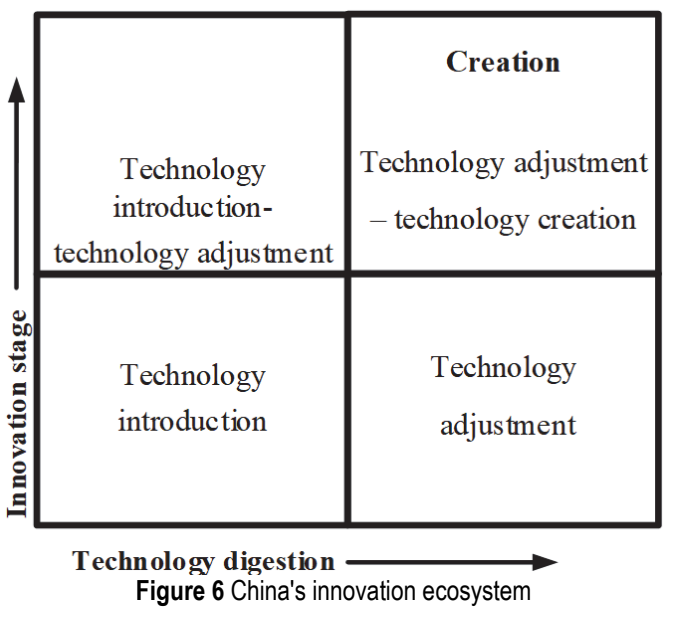

This paper proposes the relationship between the relationship network and technology digestibility of SMMEs, namely: "technology introduction - technology Creation Matrix (Fig. 6). The matrix expands from the two dimensions of relationship network and technology digestibility. The basic idea that the company's technological digestibility is positively correlated will help
China's SMMEs allocate resources and determine possible roadmaps for self-navigation from the "technology introduction" to "technology creation" step. China's SMMEs in the "technology introduction" step cannot obtain sufficient new knowledge from other aspects. Therefore, simply imitating existing products is the best choice.

1) Innovation Ecosystem- "technology introduction" step.

When determining the steps of the innovation process, the "relationship" phenomenon affects the innovation of SMMEs in China, or the "background" phenomenon, that is, government factors. In the survey of SMME business owners, it is mentioned that "relationship" is very important in the early step of product innovation. China's SMMEs with a certain "relationship" often have high sales growth. In addition, especially during the development of new products, the "relationship" network has an important influence on the acquisition of new knowledge and capital funds for SMMEs. Some interviewees in the survey said: "A good relationship with banks, government agencies, research institutions, and other organizations can help them obtain financial support and tax relief during the introduction of new technologies." SMMEs will look for related relationships to solve the company's shortcomings encountered in the development of new products. This phenomenon is closely related to the innovative background of the market economy with Chinese characteristics.

2) Innovation Ecosystem "technology adjustment technology creation" step.

The step between "technology introduction" and "technology adjustment" can be regarded as a transitional step; that is, China's SMMEs make new product innovations through small changes to existing product functions. In the "technology introduction" and "technology adjustment" phases, small and medium-sized manufacturing enterprises still have low transformation capabilities. The technological digestion ability of "technology adjustment" higher than "technology introduction" can successfully absorb external knowledge, and transform it. Therefore, SMMEs in the "technology adjustment" step can usually improve the products' main function. China's SMMEs generally have a certain degree of collaboration in the "technology adjustment" step.

SMMEs in the "technology adjustment technology innovation" step have a higher ability to transform new technologies than in the early steps. Because China's 
SMMEs have a certain "relationship" network and technology accumulation, SMMEs can easily obtain new technologies from partners to improve product innovation capabilities, so SMMEs can develop some new functions on existing products and develop unique new products by themselves. SMMEs in the "technology creation" step can design and develop new products with confidence.

3) Insufficiency of China's SMMEs in the innovation ecosystem.

Many entrepreneurs of SMMEs in China lack longterm vision. SMMEs are usually very insightful of their field, and are willing to participate more in market competition than to make personalized technological innovations for product selection in this field. It is precisely because of the lack of fierce market competition that many China's SMMEs have limited contact with the market, making it difficult to meet the needs of enterprise technological innovation and development.

Second, the lack of motivation for technological innovation makes it difficult for China's SMMEs to take innovative measures in an innovative ecological environment. Most of the SMMEs are in the rough processing step, their economic profits are low, the foundation of technological innovation is weak, and the investment in science and technology is low, which fundamentally affects the technological innovation strength of SMMEs. R\&D of most companies in China accounts for less than $1 \%$ of company sales. Therefore, it is difficult for China's SMMEs to attract technological innovation talents, resulting in a weaker foundation of innovation intelligence; China's SMMEs have too simple resources in the "relationship" network, and are relatively weak compared to large companies. Credit can cause financing difficulties. In summary, it is difficult for SMMEs to obtain financing through banks or the market, which makes it difficult for enterprises to innovate. In addition, some China's SMMEs still have the shortcoming of backward management.

4) Advantages of the innovation ecosystem with Chinese characteristics.

In the context of the "Three Innovation" slogan put forward by the Chinese government, governments at all levels regard economic transformation and development, overcapacity reduction, and industrial upgrading as important ways to enhance their innovation capabilities. In order to better understand the innovation ecosystem of China's SMMEs, this study compares the literature on product innovation steps between Japan and South Korea, which proposes an innovation ecosystem with Chinese characteristics based on China's national conditions, that is, a unique three-product innovation Development path (technology introduction technology adjustment technology creation). As the initial step of the development of product innovation, China's "technology introduction" step is mainly to produce products, which is slightly different from the technology introduction step (such as Japan). First, the Chinese government focuses on policy oriented encouragement of enterprise innovation, focuses on supporting high-tech enterprises, and adopts measures such as the integration of production, education, and research. The "technology adjustment" step is the development step of the innovation ecosystem. The creative imitation step (such as South Korea) takes the lead in policy and encourages corporate innovation. Secondly, China's large market with a population of 1.3 billion has a broad prospect, and the new products developed by SMMEs in the Chinese characteristic innovation ecosystem (in the "technology introduction" step) provide even more opportunities for SMMEs. This step is better than Japan/Korea. At this step, China's SMMEs will slightly modify existing products (for example, reduce the characteristics number of original design products). On the one hand, SMMEs will reduce the company's R\&D costs and on the other hand provide consumers with cheaper alternatives. Finally, once small and medium-sized manufacturing enterprises reach the "innovation" step, that is, the step of product innovation, SMMEs will focus on strengthening their own innovation, building multinational companies, creating a global service mindset, and providing localized services for the world market. For example, Huawei and Haier, which were initially China's SMMEs, have surpassed the creation step and have grown into hugely influential multinational companies.

In short, China's innovation ecosystem is a transition from technology imitation to technology innovation. In fact, many China's SMMEs are subject to many restrictions, such as limited technical capabilities, insufficient funds, and lack of high-quality talents, which may slow down the process of product innovation and development. Therefore, most SMMEs are in the transitional step between the "technology introduction" and "technology adjustment" of the innovation ecosystem, that is, starting from more imitations, and then carrying out some incremental innovations, mainly for local market demand. China's SMMEs often emphasize efficiency-driven innovation to maintain low costs, ensure product quality, and shorten the time to market. SMMEs usually implement product improvements through customer feedback, and SMMEs rarely or even never conduct scientific research to carry out technological innovation. In general, this study found that many SMMEs are in a transitional step, that is, between "technology introduction" and "technology adjustment", and SMMEs are often low value-added production enterprises and "SHANZHAI" manufacturers. The step between "technology adjustment" and "technology creation" is often for high-tech companies, such as Huawei. This paper studies the three steps of product innovation and development specific to SMMEs under the Chinese market economy. Since the focus of the research is on SMMEs in China, the research results may not be applicable to the development of SMMEs in the world, but these three unique steps may be applicable to SMMEs in the Far East such as Malaysia and Vietnam. China's innovation ecosystem development can promote economic innovation and prosperity in many developing countries.

\section{CONCLUSION}

The formulation of the development policy of the country's small and medium-sized manufacturing enterprises has not integrated with the national development plan, and the research on the innovation ecology of enterprises has not reached the strategic level of national development. The research on the innovation ecosystem with Chinese characteristics carried out in this article has some limitations, especially the research on the 
experience and lessons of China's SMMEs.

First, the sample size of this study is small, and it is only for the relevant China's SMMEs in Suzhou. This paper urgently needs to collect a larger sample size from the whole country for further research. Secondly, eastern China has a developed economy and strong local government policy support, resulting in obvious regional economic differences. In the future, the research on the innovation power of SMMEs in the central and western regions should be put first. In addition, this paper did not study the relationship between the development step of product innovation and the "relationship" network in more depth, especially in the relatively backward areas in the Midwestern China. Therefore, fully understanding the innovation dynamics and actual conditions of various regions in China and actively promoting the research of Chinese innovation ecosystem will better help governments at all levels to carry out policy guidance work and guide the local economy and even the national economic development.

\section{REFERENCES}

[1] Liang, M., Jin, C., \& Yang, L. (2014). Innovation Ecosystem: Origin, Knowledge Evolution and Theoretical Framework. Studies in Science of Science, 12, 1771-1780.

[2] Tang, J. \& Li, X. (2016). Synergy evaluation of industrial ecosystem and diagnosis of obstacle factors-Based on the empirical analysis of 16 cities in Anhui Province from 2005 to 2014. East China Economic Management, 11, 17-25.

[3] Qiwei, L., Xin, G., \& Changyi, Z. (2017). Influencing Factors of Knowledge Advantage in Industrial Innovation Ecosystem: Theoretical Framework and Empirical Research. Research on Economic, 9, 163-174.

[4] Liu, G. (2009). Research on the Science and Technology Innovation Policy of Small and Medium-sized Manufacturing Enterprises in my country. Tianjin University.

[5] Jiang, Q. (2018). Research on the Construction and Evaluation of China's Innovation Ecosystem. Economic Survey, 35(04), 1-8.

[6] McKinsey Global Institute. (2015). The China Effect on Global Innovation. McKinsey \& Company. http://www.mckinseychina.com/wpcontent/uploads/2015/0 7/mckinsey-china-effect-on-global-innovation-2015.pdf? bd0bde (Accessed on 15 January 2016).

[7] Cheung, T. M. (2011). The Chinese defence economy's long march from imitation to innovation. J. Strateg. Stud., 34(3), 325-354. https://doi.org/10.1080/01402390.2011.574976

[8] China State Council. (2015). Made in China 2025. White Paper.http://english.gov.cn/policies/latest_releases/2015/05/ 19/content 281475110703534.htm (Accessed on 1 July 2015).

[9] Chinese statistics year book. (2011). National Bureau of Statistics of China. http://www.stats.gov.cn/tjsj/ndsj/2011/indexeh.htm (Accessed on 1 May 2015).

[10] Freel, M. S. (2000). Barriers to product innovation in small manufacturing firms. Int. Small Bus. J., 18, 60-80. https://doi.org/10.1177/026624268200100105

[11] Siu, W. S., Lin, T., Fang, W., \& Liu, Z. C. (2006). An institutional analysis of the new product development process of small and medium enterprises (SMEs) in China, Hong Kong and Taiwan. Industrial Marketing Management, 35(3), 323-335. https://doi.org/10.1016/j.indmarman.2005.04.008

\section{Contact information:}

\section{Yu WANG}

(Corresponding author)

School of Marxism, Hohai University, Nanjing, 211100 China Nanjing University of Finance and Economics, Nanjing, 210003 China

E-mail: wangyu@nufe.edu.cn 